\title{
A DIVERSE APPROACH FOR INDUSTRY 4.0 VIA FEM THERMAL ANALYSIS
}

\author{
YURCI, C.
}

Abstract: One of the primary objects during the treat Industry 4.0 is providing a higher energy efficiency through Energy Management execution. In the context of that study, related ISO Standards in the field Energy, Quality and Environmental Management Systems are referred. Followingly, the welding process, handled in that study, is a conventional primary production method applied with the incorporated automation systems of Industry 4.0. So, as a Finite Element Thermal Analysis sub-model, a 'Laser Welding Case' has been selected. Followingly, the whole Industry Process Idea is reached step by step from an incipient manufacturing unit, according to the basic principles of Industry 4.0 including a general performance investigation in the aspect of energy management. Also, that bottom up method can be described as 'an approach over an inverted hierarchy pyramid-like logic' as well.

Key words: Industry 4.0, Energy Management, Thermal Analysis, Laser Spot Welding, Hierarchical Approach
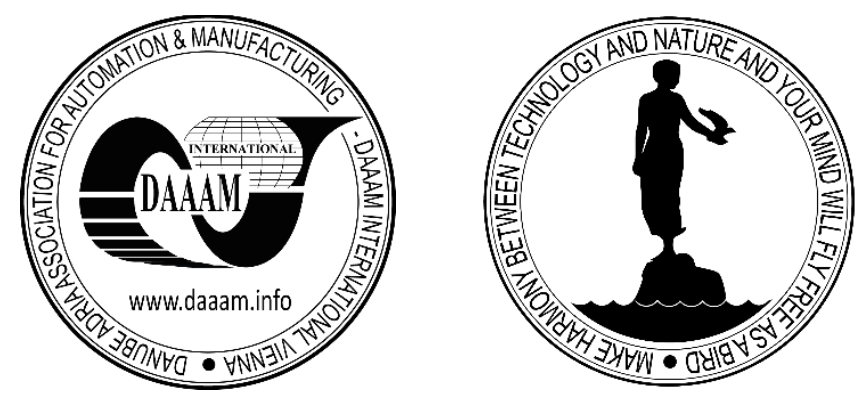

Authors' data: Dr. Yurci, C[em], Yildiz Technical University, Barbaros Bulvari, Yildiz, 34349, Istanbul, Turkey, yurci_cem@yahoo.com

This Publication has to be referred as: Yurci, C[em] (2020). A Diverse Approach for Industry 4.0 via FEM Thermal Analysis, Chapter 09 in DAAAM International Scientific Book 2020, pp.113-130, B. Katalinic (Ed.), Published by DAAAM International, ISBN 978-3-902734-27-3, ISSN 1726-9687, Vienna, Austria DOI: $10.2507 /$ daaam.scibook.2020.09 


\section{Introduction}

Today, the effects of the recent revolution Industry 4.0 can be perceived and observed obviously and intensely worldwide especially in developed regions. Production industry people prefer adapting to this new crucial organization, gladly or necessarily. Lately an indispensable improvement for this route is chosen to supply enormous favours despite its huge investment requirement.

That study is handled in the combined context of Industry 4.0 and a manufacturing process method. That method is considered as Laser Beam Welding and will be evaluated in the scope of Energy Management. During that, the necessary relationships are established within the rules of relevant Standards and Guidelines. The main object is to present a different hierarchical view angle for Industry 4.0 Components and their contribution to energy winnings. The main reason for that is the need of digitalization of welding processes' Planning and Optimization in accordance with the notions of Industry 4.0.

\subsection{Industry 4.0 Components Overview}

(Vancuhkhina et al., 2109) state that at the end of the initial industrial revolutions, processes such as electric mobility, information economy, change of technological modes and cyclicity of economic development pushed the megatrend 'Industry 4.0' of the modern global evolution. During that act, (Akopova \& Przhedetskaya, 2019) propose to all the employees evolving themselves according to the components and rules of Industry 4.0, as production functions are being automatized. Certainly, they are adapting so themselves to the innovative technological elements of Industry 4.0, such as Big Data, IoT and Cloud Computing. Such tools are helping to other tools of Industry 4.0 by implementing their roles collectively. Simulation can be accepted as one of those.

Simulation is employed recently under the umbrella of Industry 4.0 in many areas with several purposes. These fields and tools, essential for Industry 4.0, are counted by (Gunal, 2019) as 'Cyber Physical Systems and Digital Twin', 'Vertical and Horizontal Systems Integration and Hybrid Modelling', 'Augmented Reality/Virtual Reality (AR/VR) and Training People', 'Cloud, Big Data Analytics and Simulation Input Modelling', 'Internet of Things (IoT) and Designing Connectivity', 'Additive Manufacturing and Product Design'. The application of simulation, for the given example by (Gunal \& Karatas, 2019) in Supply Chain and Lean Manufacturing triggered the rise of numbers of research papers about that subject and is pushing the digitisation in manufacturing and data analytics forwards. In addition, some sample studies are of (Vieira et al., 2019) simulating an automotive supply chain using big data and of (Mourtzis et al., 2019) et al. designing a manufacturing system using Simulation in metal industry towards Industry 4.0 for a Teaching Factory. In the last study, the simulation procedure is divided into the stages 'Simulation Model', 'Data Analysis and Distribution Fitting', 'Validation and What-if Scenarios Experiments' and 'Statistical 
Design of Experiments'. However, the subject of that study can be accepted again as a digital twin of a manufacturing process modelled with concrete, definite and close to real life parameters and the instantiated simulation results as a too much small portion of Data (or Big Data sample) which can be utilized for other connected production phases and stages. As a good example, (Rodič, 2017) gives place to 'Digital Twinning' (with the subprocesses 'Digital Shadow' and 'Digital Master') between the phases 'Online Business Database' and 'Decision Support Tools' including for instance, Machine Learning Optimisation. Also, (Durakbasa et al., 2017) state that AI and modern IT support the realisation and integration of modern cost-effective customerdriven design and manufacturing. During that, they count 'Simulation' in the model of a NGF (Next Generation Factory) besides other components such as Intelligent Metrology, Process Approach, System Integration and Quality Autonomation.

\subsection{Industry 4.0 in the context of Standards including Energy}

All the objects of industrial activities are to improve financial standards and gains by providing a collaborative organisation and reducing the costs through digitization and automatization. Meanwhile, the quality standards have to be considered to sustain factory standards in a healthy and satisfactory way. Also, one of the most important guides is the (DIN EN ISO 9001) Standard which is conducting Quality Management Systems. A quality management system enables finally the improvement of processes based on evaluation of data and information through tools such as 'Plan-Do-CheckAct' (PDCA) cycle by implementing its requirements. Also, the aims interconnect with Industry 4.0.

More concrete conclusions of the study can be evaluated and obtained towards standards related with Energy. In that context, (DIN EN ISO 50001) Standard states the requirements with guidance for use by Energy Management Systems. Accordingly, the importance of two specifications 'Energy Performance Indicators' (EnPIs) and Energy Baselines (EnBs) in the Plan stage of PDCA Cycle are stated to achieve the goals, energy targets and action plans that are necessary for improving energy-related performance in accordance with the organisation's energy policy. Moreover, (DIN EN ISO 50006) gives more specific samples, ways and scenarios for the measuring of EnPI and EnBs values. As a helpful standard, (ISO FDIS 50004) guides for the implementation, maintenance and improvement of an ISO 50001 energy management system by introducing details about energy targets and planning, analysis of energy use and consumption. Even, (ISO/FDIS 50004) supports that information accumulation with support, operation, performance evaluation and improvement instructions for implementing of a common energy system by multiple organisations. In addition, Energy Audits take a significant role by the production management and its required processes on the production line are presented in the standard (DIN EN ISO 50002). All of these standards unite by the object 'high effectiveness' of the energy management in a stage-by stage idea gradually and collaboratively. 
There is not any determined standard belonging definitely to the subject 'Industry 4.0'. But there are guidelines investigating Industry 4.0 cases. For example, (VDI 5600-Part 7) informs the users about Manufacturing Execution Systems (MES) integrated with Industry 4.0. One of the case studies in that guide about dynamic detailed planning in production proves that through better networking of the individual components, involved in production, and the use of more sensors in the machines and systems, more information is available that enables continuous transparency. Based on this end-to-end transparency, the MES can then carry out re-planning step by step independently, initially with learned algorithms and later using AI. Previously, Part 6 of the same guide, (VDI 5600-Part 6) states fundamental 'Energy Management with MES' knowledge consisting objectives, parameters, functions and benefits in a way similar to former mentioned standards. As one of the components playing the most important roles in Industry 4.0, Big Data is explained by the parts, (VDI/VDE 3714Part 1) and (VDI/VDE 3714-Part 2) through its implementation and operation in the manufacturing industry including its projects and data quality. However, DIN SPECs are present to assist to the Industry 4.0 people. In that way, (DIN SPEC 3103) exemplifies Blockchain and distributed ledger technologies by Industry 4.0 in application scenarios such as order-controlled production, self-organizing adaptive logistics, value-based services, smart product development for smart production and innovative product development. Moreover, (DIN SPEC 16593-1) details the Reference Model for Industry 4.0 Service Architectures consisting Reference Architecture Model Industry 4.0 (RAMI4.0).

In all these activities, environmental balance and rules have to be respected and considered as well. During that treat, (DIN ISO EN 14001) guides with requirements for environmental management systems. Although its main methods are similar to other management systems, it includes several commitments' targets like protection of the environment, prevention of pollution, enabling of sustainable resource use and climate change mitigation and adaptation, protecting of biodiversity and ecosystems.

\subsection{Laser Beam Welding and its Computational Simulation}

Laser Beam Welding can be adopted as a new welding method and is applied recently due to its superior advantages instead of corresponding classical welding ways. Its main reason is the very high-power density of a laser beam, when compared that of arc or plasma. Consequently, a deep and narrow Key Hole occurs during laser welding satisfying an effective deep, narrow penetration including a high travelling speed, according to (Katayama, 2013). However, laser beam welding needs a big investment and is suitable for small parts. But its benefits can be arranged with choosing its appropriate method. Their types are given by (Katayama, 2013) as CO2 Laser, YAG Laser and Laser Diode, Disk Laser and Fiber Laser. They are distinguished according to their wavelength, laser media and average power. (Katayama, 2013) also adds that laser welding is also applicable to the joining of similar or dissimilar materials such as plastics, cast irons and steels, steels and aluminium alloys, or metals and plastics. Here is the feasibility of the production of a strong joint is important. In 
addition, (Szuhanek, 2010) counted another advantage of laser welding as no need for soldering and so no galvanic corrosion at the joint and used it for welding of orthodontic metal appliances.

Depending on the laser irradiation time and the power density, a spot or bead weld is formed in the morphology of a heat-conduction type or a keyhole type as shown in Fig. 1 . The temperature of the plate surface rises by the transfer from laser energy to thermal energy.

a)

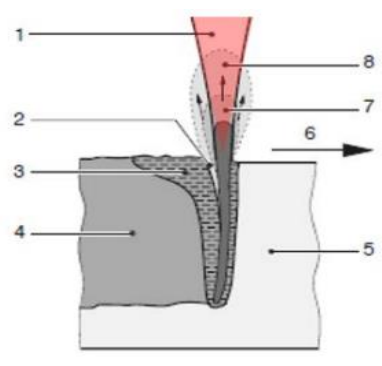

b)

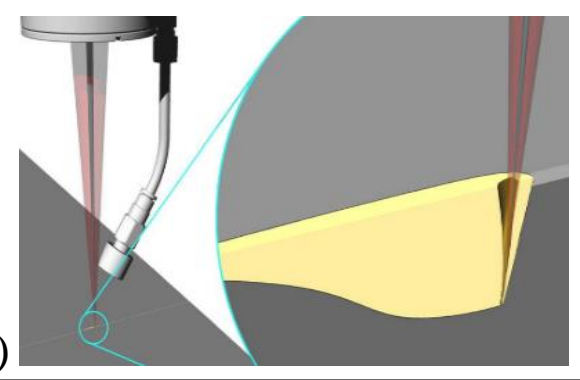

Fig. 1. a) (IPG Photonics Eurasia Laser Products-Database) 1. Laser Beam 2. Key Hole 3. Melt Pool 4. Solidification 5. Workpiece 6. Moving Direction 7. Metal Vapour 8. Plasma Cloud b) (Heston, 2020) Inline Coherent Imaging apparatus follows the beam path and measures weld penetration towards the Key Hole.

The laser irradiation time and the power density determine whether a spot or bead weld is formed according to the morphology of a heat-conduction type or a keyhole type. That procedure is explained by (Katayama, 2013) again detailly including the following stages. When a laser beam is shot on the metallic plate, the movement of free electrons in the metal provides the absorption of laser energy. That electrons transfer like in the form of a band, and the interaction of those electrons with metal lattice, defects, imperfection rises the temperature of the plate surface by which the transfer from laser energy to thermal energy. So, the laser absorption increases together with the temperature in the solid zone and even in a large extent above the melting temperature. After that, the temperature of the laser-irradiated area reaches to the values higher to the boiling point. A cavity or a keyhole occurs affected by rebound pressure due to evaporation.

The investigated laser type in that study has been considered as YAG Laser. Compared to $\mathrm{CO} 2$ lasers, the greater ability of YAG Laser to convey the wavelength (Nd-YAG: emitting in the near infrared region in the range of 1.03-1.07 micron) with a fibre presents an advantage for industrial applications particularly when anthropomorphic robots are used, according to (Fabbro, 2013). The heat conduction from the focal spot and welding speed determine the size of the melt pool. The laser intensity generates a high evaporation rate and so the melt pool surface is depressed and so the laser beam is able to penetrate deeply inside the material. Key Hole generation is therefore the basic mechanism by laser welding. That is a complex process compounding from physical mechanisms such as laser absorption, conductive and convective heat transfer, a complex hydrodynamic flow around the Key Hole and 
inside the melt pool, and an interaction of the vapour plume with the melt pool. The Key Hole provides the propagation of the laser radiation trough the keyhole channel and so the direct absorption inside the material can be achieved besides the powerful and rapid evaporation (Stanciu et al., 2010). The dominant mechanisms during that process are laser absorption at the melt pool surface and conductive heat flow inside the melt. Moreover, (Fabbro, 2013) asserts that although, its hydrodynamics is controlled by Marangoni surface effect, that effect is not singly observed in the case of Key Hole welding.

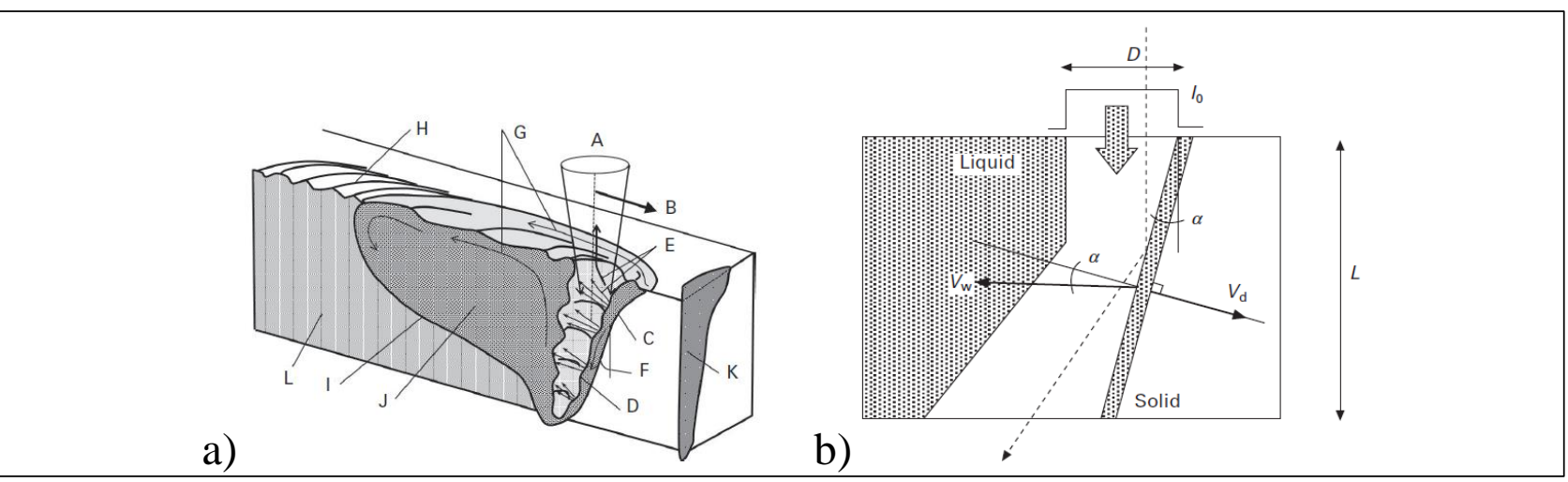

Fig. 2. (a) 3D sketch of laser welding: A: Laser beam; B: Welding speed; C: KH front; D: Humps; E: Vapour jets; F: (Key Hole Front Wall inclination; G: Melt flow; $\mathrm{H}$ : Chevron structure; I: Solidification front; J: Melt pool; K: Weld seam cross section; L: Resolidified material. (b) Scheme of the longitudinal section of a keyhole in a case of full penetration (Fabbro, 2013).

In Fig. 2, the laser beam has a uniform intensity $\mathrm{I}_{0}$ whose diameter is $\mathrm{D}$. In that sketch, the molten material is moving from right to left with the welding speed $\mathrm{V}_{\mathrm{w}}$. So, the reflected beam enlarges the bottom of the Key Hole. As a result, the dependence on penetration depth $\mathrm{L}$ with the main operating parameters will be:

$$
\mathrm{L} \approx \mathrm{k} \mathrm{I}_{0} \mathrm{~A}_{0} \mathrm{D} / \mathrm{V}_{\mathrm{w}}=\left(4 \mathrm{~A}_{0} \mathrm{k} / \Pi\right) \cdot \mathrm{P} /\left(\mathrm{D} \cdot \mathrm{V}_{\mathrm{w}}\right) \mathrm{z}
$$

In Eq. (1), the parameter $\mathrm{k}$ is a proportionality factor between the drilling speed $\mathrm{V}_{\mathrm{d}}$ and the absorbed intensity:

$\mathrm{V}_{\mathrm{d}} \approx \mathrm{k} \cdot \mathrm{I}_{\mathrm{abs}}$

The factor k represents the energy balance of the process that is dependent mainly on the workpiece material. According to (Fabbro, 2013), it can be determined experimentally for similar conditions of incident laser intensity (approximately $\mathrm{k} \approx 3$ $\mathrm{X} 10^{-11} \mathrm{~m}^{3} / \mathrm{J}$ for 304 stainless steel). Here, $\mathrm{I}_{\mathrm{abs}}$ illustrates the absorbed laser intensity.

(Goldak \& Akhlagi, b, 2010) assert that Computer Simulation of welding processes has been a crucial stage for functional tools in design and for planning of manufacturing. This step includes the coupling between thermal, mechanical and 
microstructure effects. Also, (Goldak \& Akhlagi, 2010a) add that Computational Welding Mechanics is settled on the disciplines such as numerical methods, algorithms computer programs, stress-strain, boundary conditions, microstructure, heat transfer and boundary conditions. By heat transfer analysis in welding, the given main models by (Goldak \& Akhlagi, 2010b) for welding heat sources related by heat flow, which was developed by Fourier, are Gaussian Surface Flux Distribution, Hemi-spherical, Ellipsoidal and Double Ellipsoidal Power Density Distribution.

(Wang, 2013) explained a sample laser beam welding simulation and its results compared with the those of real laser lap welding of stainless steel vehicles by railway industry. The boundary condition equation for that, given by (Wang, 2013) in Eq. 3, where the laser heating, the welding surface convection and radiation heat transfer [26] are shown towards $\mathrm{T}_{\mathrm{s}}$ (surface temperature), $\mathrm{T}_{\mathrm{ext}}$ (the ambient temperature), $\mathrm{h}$ (the convective heat transfer), s (the Stefan-Boltzmann constant), and $\varepsilon$ (the thermal radiation coefficient).

$$
-k_{e} \frac{\partial T}{\partial z}+h\left(T_{s}-T_{e x t}\right)+\sigma \varepsilon\left(T^{4}-T_{e x t}^{4}\right)=\mathrm{q}
$$

By the sample of (Wang, 2013), considering the shape of the weld, the heat source model in Fig. 3 is chosen. That model is combined of three-dimensional positive cone, 3D inverted cone and half-ellipsoid heat source. The three-dimensional cone heat equations can be given according to (Wang, 2013) so:

$$
\begin{aligned}
& r_{0}(z)=r_{e}-\left(r_{e}-r_{i}\right) \frac{z_{e}-z}{z_{e}-z_{i}} \\
& q(r, z)=\frac{9 Q e^{3}}{\pi H\left(e^{3}-1\right)\left(r_{e}^{2}+r_{e} r_{i}+r_{i}^{2}\right)} \exp \left(-\frac{3 r^{2}}{r_{0}^{2}}\right)
\end{aligned}
$$

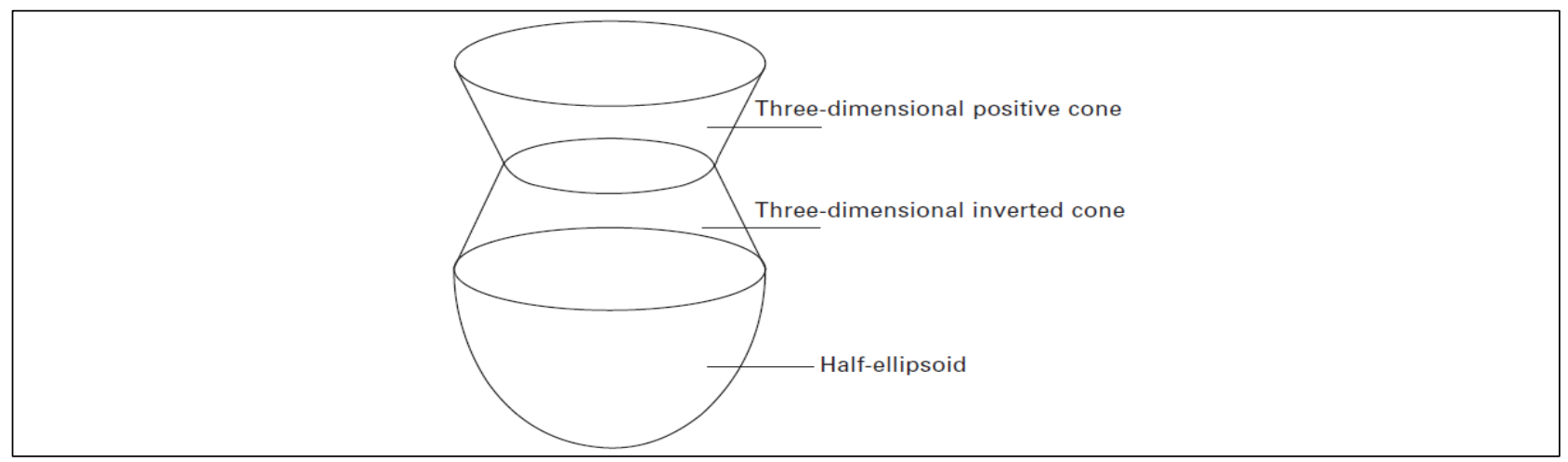

Fig. 3. Combination of heat sources

In those equations, $\mathrm{z}_{\mathrm{e}}, \mathrm{z}_{\mathrm{i}}$ and $\mathrm{z}$ are representing coordinate positions of the laser heat source positions on the surface of the workpiece, $r_{e}, r_{i}$ show the radii of the heat source distribution. All the parameters are determined through experience and the test results. 
The ellipsoid heat source formula is given in Eq. (6), in which where $a_{h}, b_{h}$ and $\mathrm{c}_{\mathrm{h}}$, respectively, are the half axle lengths in the $\mathrm{y}, \mathrm{x}$ and $\mathrm{z}$ directions, respectively.

$$
q(x, y, z)=\frac{6 \sqrt{3} Q}{a_{h} b_{h} c_{h} \pi \sqrt{\pi}} \exp \left(-\frac{3 x^{2}}{b_{h}^{2}}-\frac{3 y^{2}}{a_{h}^{2}}-\frac{3 z^{2}}{c_{h}^{2}}\right)
$$

Additionally, (Kristensen, 2013) and (NA \& Cho, 2013) give other simulation examples for the shipbuilding industry and for laser hybrid welding, respectively. (Kelly et al., 2011) also tries to minimize the buckling distortion in welding by laserarc welding through experimental and analytical weld distortion data.

\section{FEA Analysis Procedure for Sample Laser Welding Cases}

Laser Welding FEA has been carried out in Simufact Welding 8.0. Four analyses have been created with parameters inspired from the references (Landowski, 2019), (Yilbas, 2013) and (Xin et al., 2017) as a model only on simple coupons with the thickness $1 \mathrm{~mm}$. Their dimensions (Fig. 4) have been extracted from the standard (DIN EN ISO 14373) for resistance welding applications because there is not a direct standard for laser welding implementations.

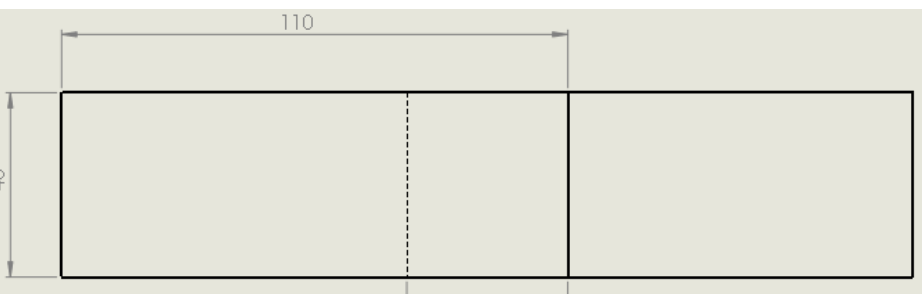

Fig. 4. The dimensions of sample coupons

Those four analyses' welding, heat source and general parameter values are given in Tab. 1, Tab. 2 and Tab. 3, respectively.

\begin{tabular}{|c|c|c|c|c|}
\hline Analysis Instance & $\begin{array}{c}\text { Number of } \\
\text { Welding Spots }\end{array}$ & $\begin{array}{c}\text { Energy } \\
(\mathrm{W})\end{array}$ & $\begin{array}{c}\text { Energy } \\
\text { Efficiency }\end{array}$ & $\begin{array}{c}\text { Welding Velocity } \\
(\mathrm{mm} / \mathrm{s})\end{array}$ \\
\hline Type 1 & 1 & 2000 & 0.8 & 30 \\
\hline Type 2 & 1 & 3000 & 0.8 & 30 \\
\hline Type 3 & 2 & 2000 & 0.8 & 30 \\
\hline Type 4 & 2 & 3000 & 0.8 & 30 \\
\hline
\end{tabular}

Tab. 1. Welding Parameters of the Welding Process

Before the analysis, the valid heat source has been accepted as cylindrical heat source including the heat source parameters in Tab. 2 according to Fig. 5.

\begin{tabular}{|l|l|c|}
\hline \multirow{4}{*}{ Volumetric heat source } & Conical heat source upper radius $\mathrm{r}_{\mathrm{u}}$ & 0.7 \\
\cline { 2 - 3 } & Conical heat source lower radius $\mathrm{r}_{1}$ & 0.7 \\
\cline { 2 - 3 } & Conical heat source depth $\mathrm{d}$ & 2.0 \\
\cline { 2 - 3 } & Gaussian parameter M & 0.0 \\
\cline { 2 - 3 } & Volume heat fraction & 1.0 \\
\hline
\end{tabular}




\begin{tabular}{|c|l|c|}
\hline \multirow{3}{*}{ Surface heat source } & Disc Radius $\mathrm{r}$ & 0.7 \\
\cline { 2 - 3 } & Surface heat source depth & 0.6 \\
\cline { 2 - 3 } & Gaussian parameter M & 3.0 \\
\hline
\end{tabular}

Tab. 2. Heat Source Parameters of the Welding Process

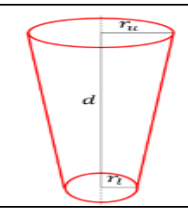

Fig. 5. Conical heat source model schematics for 'Simufact Welding'

The designed laser beam welding process has been considered as YAG-laser process consisting AR as shielding gas and other general parameters presented in Tab. 3.

\begin{tabular}{|c|c|}
\hline Manufacturing method & Manual \\
\hline Welding position & PA - flat \\
\hline Gap Size & $1.0 \mathrm{~mm}$ \\
\hline Filler material & Ti-6Al-4V \\
\hline Wire size & $0.5 \mathrm{~mm}$ \\
\hline Wire feed velocity & $6.0 \mathrm{~m} / \mathrm{min}$ \\
\hline Shielding gas & $\mathrm{Ar}$ \\
\hline Shielding gas flow & $20.01 / \mathrm{min}$ \\
\hline Filler throat & $0.0 \mathrm{~mm}$ \\
\hline Filler bow & $0.0 \mathrm{~mm}$ \\
\hline Leg lengths of the filler & $0.0 \mathrm{~mm}$ \\
\hline
\end{tabular}

Tab. 3. General Properties of the Welding Process

The aim of that study was to inspect a laser spot welding process regarding to heat flux fundamentals. However, because of the limitations of the used FEA software the laser spot has to be handled as a laser beam. So, the beam trajectory has been formed in the form of a spot generated from small pitches to create a welding circle (Fig.6).

Fig. 6. Welding Spot generated as a beam trajectory in Simufact Welding

As in Fig. 7 and Fig. 8, two clampings are observed in the model view of the designed process. These clampings have the translational stiffness of $1000 \mathrm{~N} / \mathrm{m}$ and 
are activated all the welding time including the cooling times. As it is seen in the same figure, a sheetmesh of hexahedral type with the element size of $4 \mathrm{~mm}$ is attained to the sheet metal parts. However, elements' counts are increased within the welding heat source radius towards a refinement of ' 2 ' and to provide more reliable results.

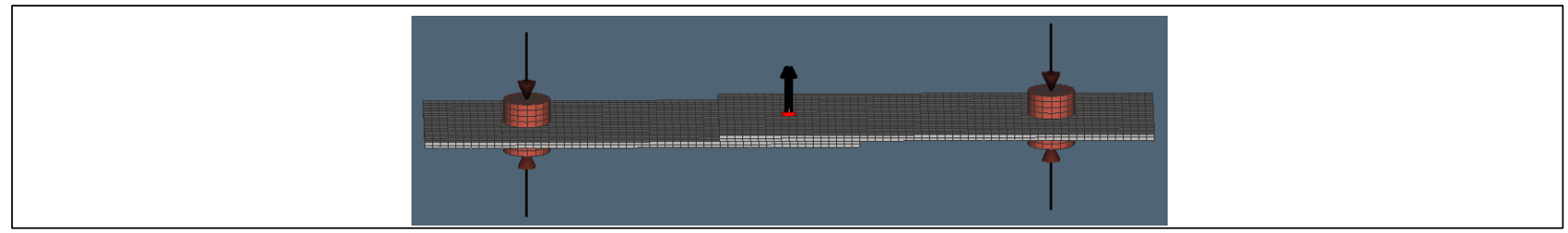

Fig. 7. Model View of the generated Laser welding process for one welding spot (Type 1-2)

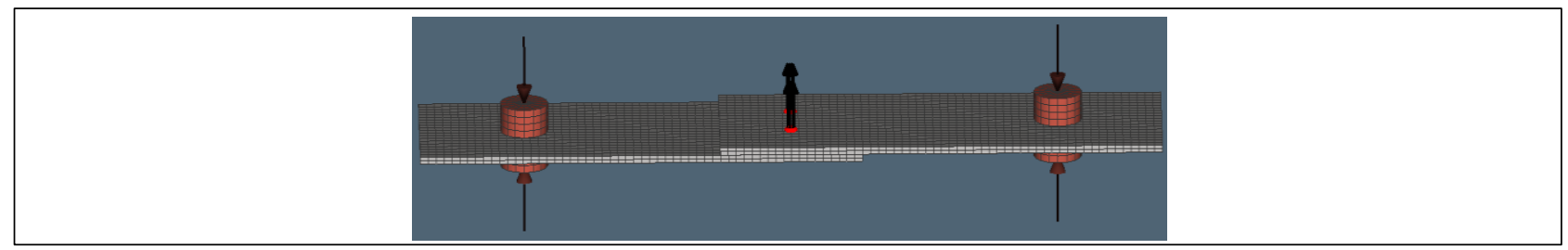

Fig. 8. Model View of the generated Laser welding process for two welding spots (Type 3-4)

During the process, the ambient temperature is accepted as $20^{\circ} \mathrm{C}$. The material of sheet material parts is exported from the material library of the used software as the austenitic stainless steel ' $316 \mathrm{H}$ '.

The welding time for one trajectory has been calculated by the software as ' 0.2083 s' automatically. For two spots, the pause time has been selected as ' $0.5 \mathrm{~s}$ '. All the simulations have been run for totally $10 \mathrm{~s}$ including cooling times.

Thermomechanical simulation is chosen for simulation configuration to see the integrated results of both mechanical and thermal effects. Additionally, the selected matrix solver type is Pardiso Direct Sparse enclosing the friction implementation 'bilinear approach-Coulomb friction model' and the plasticity solution 'multiplicative plasticity'.

\section{Results}

\subsection{FEA Analysis Results during the Weld Period}

Due to the object of the study, prominently thermal analysis results are considered. In Fig. 9, the temperature results for all the analysis types can be seen. 


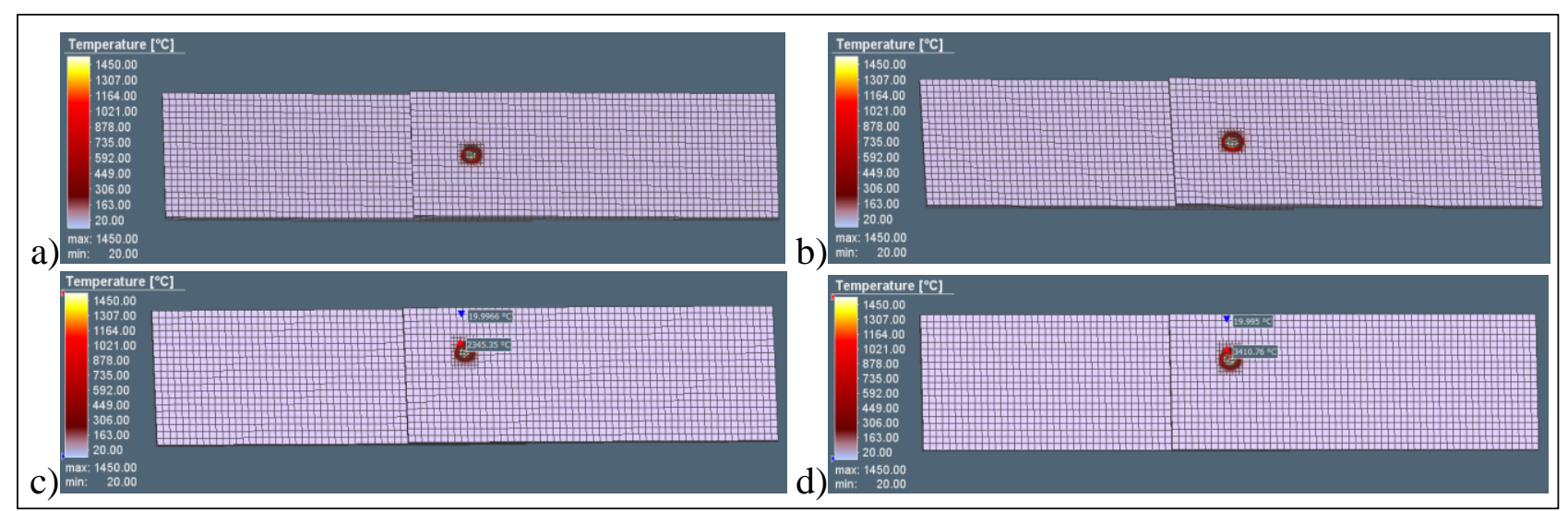

Fig. 9. Temperature Distribution during Welding after $0.168 \mathrm{~s}$ on the Sheets for a) Type 1, b) Type 2, (c) Type 3 and d) Type 4

As it is seen in the figures above, a similar temperature distribution is generated on the weld region. Peak temperature for Type 3 is at the observed moment ' 2345.35 'C' while that temperature increases to $3410.76{ }^{\circ} \mathrm{C}$ when the weld energy amount reaches to one and a half times of the first value.

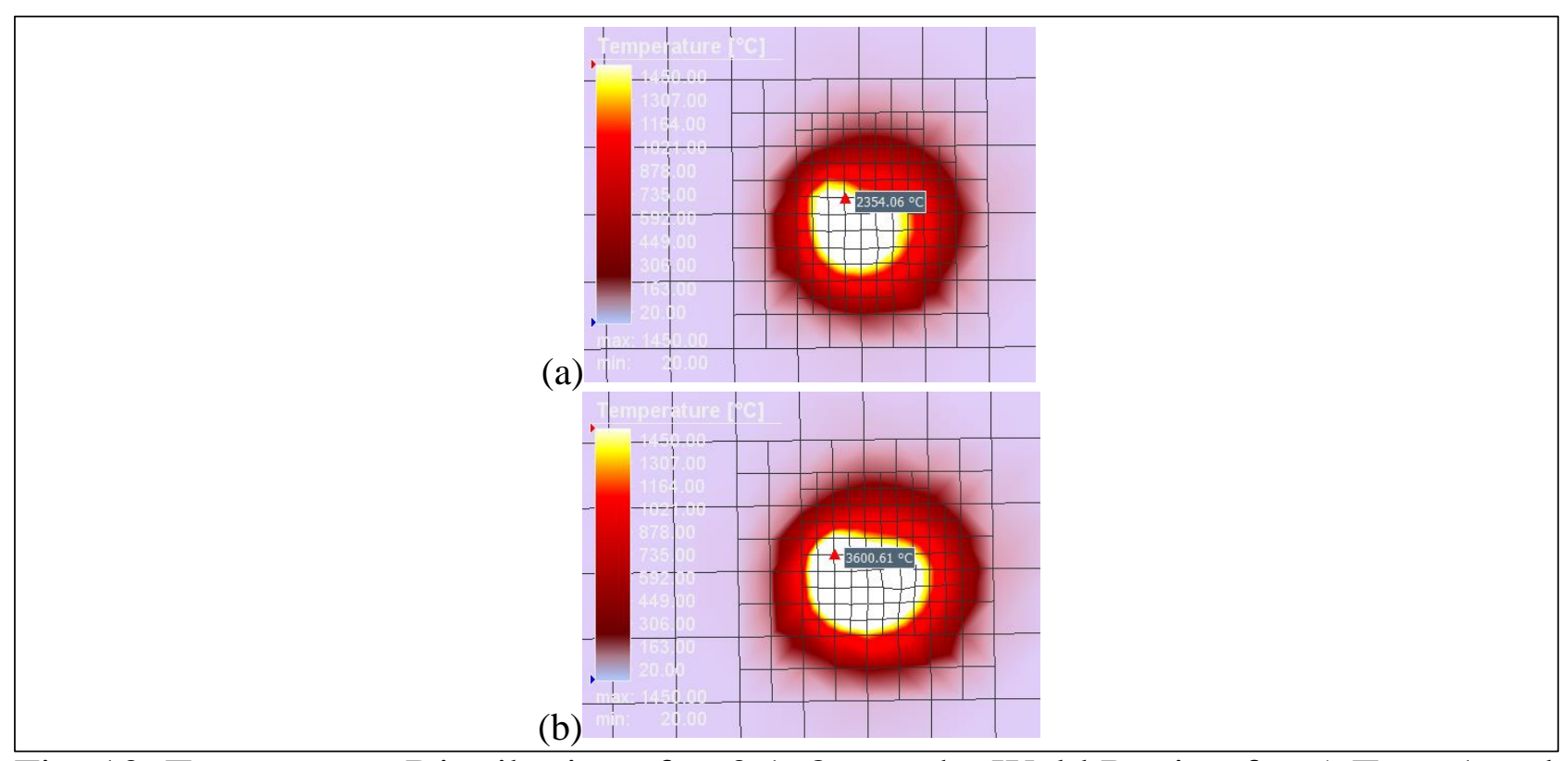

Fig. 10. Temperature Distribution after $0.168 \mathrm{~s}$ on the Weld Region for a) Type 1 and b) Type 2

White regions in Fig. 10 indicate the melt zone. If the weld energy is raised, the melt zone and peak temperatures in that area are increasing as well, inherently. 
Yurci, C.: A Diverse Approach for Industry 4.0 via FEM Thermal Analysis

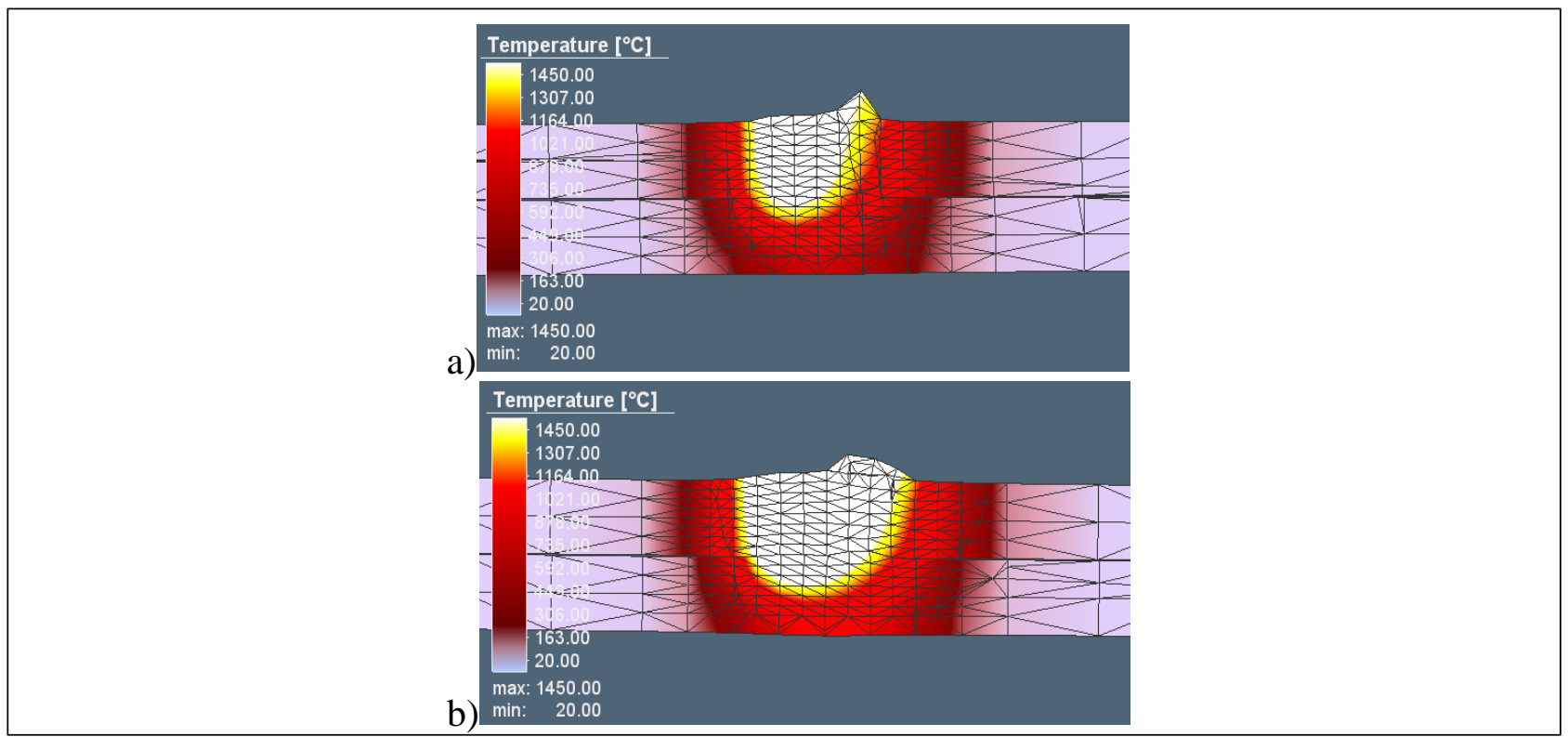

Fig. 11. Temperature Distribution for the cross-sectional weld area after ' $0.2083 \mathrm{~s}$ ' at the end of welding for (a) Type 1 and (b) Type 2

Similar observations in Fig. 10 can be made for Fig. 11 as well. During that, the increasing dimensions of the penetrating melt zone into the sheet metal below stand out by the cross-sectional view for the last welding point.

\subsection{FEA Analysis Results during the Cooling Period}

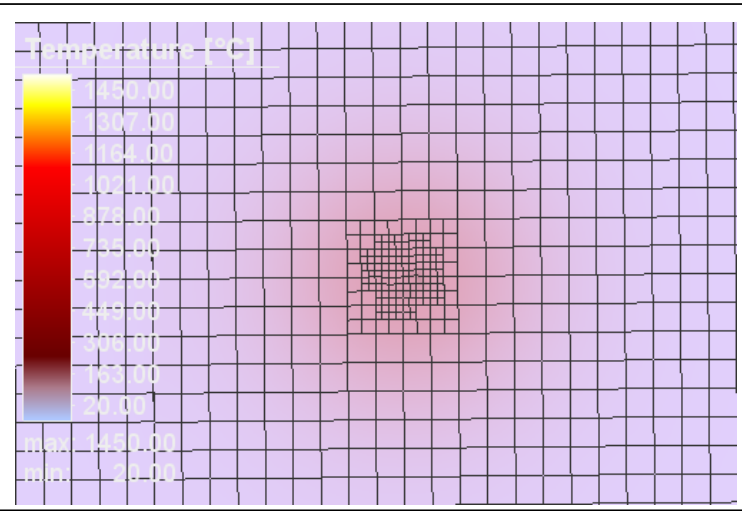

Figure 12. Temperature Distribution after $10 \mathrm{~s}$ on the Weld Region for Type 1

By one laser spot and energy input of $2000 \mathrm{~W}$, the dispersed temperature decreases under the value of $82^{\circ} \mathrm{C}$ approximately after $10 \mathrm{~s}$ (Fig. 12). 


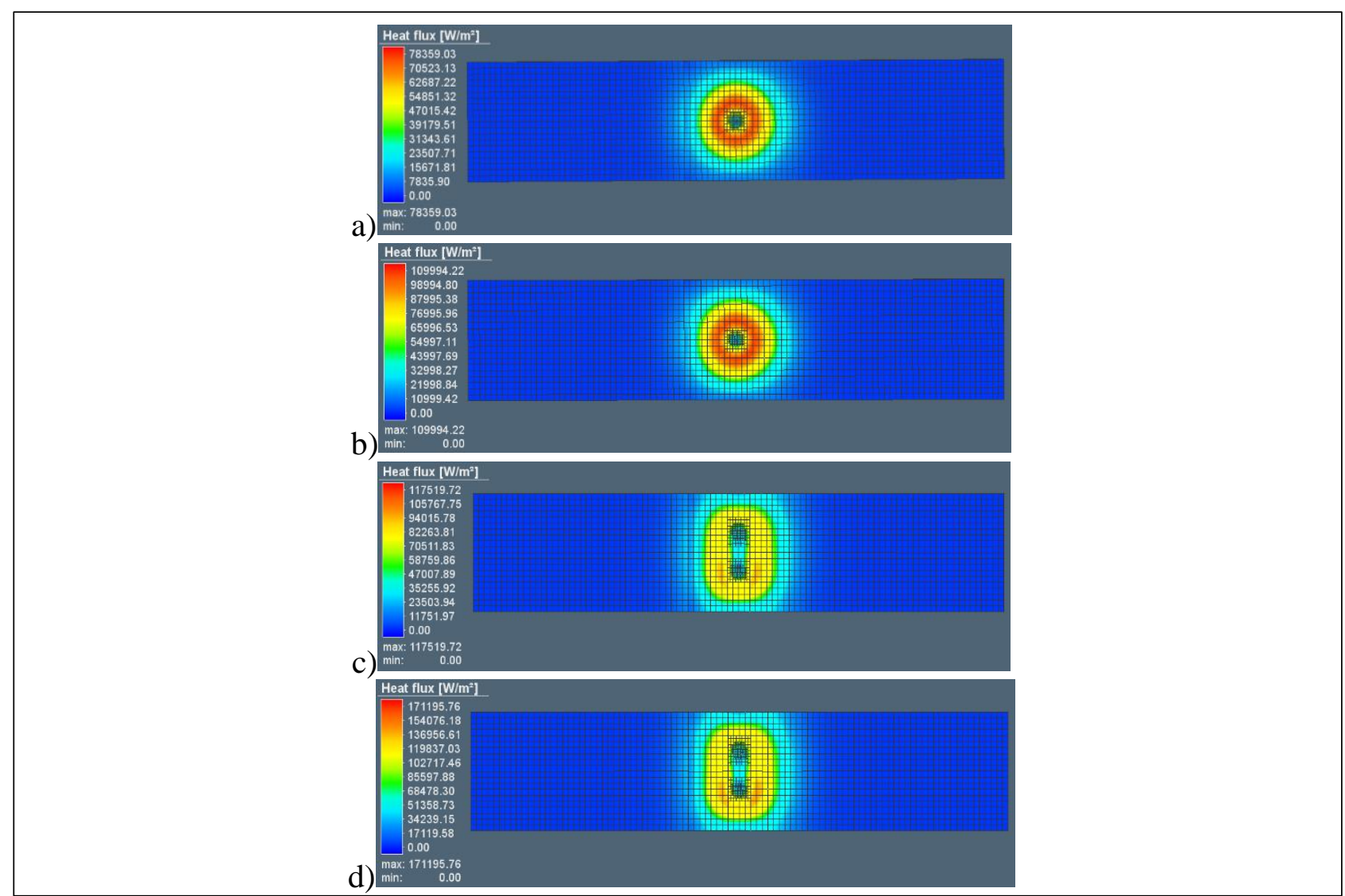

Fig. 13. Heat Flux Distribution after $10 \mathrm{~s}$ on the Sheets for a) Type 1, b) Type 2, c) Type 3 and d) Type 4

As it has been expected, the dispersing heat flux is increasing by a factor little less than the multiple by which the energy input rises. The factor of the number of spots is more important because that influences on the heat amount more significantly. Naturally during that, the shape, dimensions of weld trajectories, heat source model geometry and dimensions play other definite roles. The radial heat dispersion transforms to a conjunction for both weld trajectories. The temperature and heat values in both Fig. 12 and Fig. 13 will decrease if the cooling time in the analysis and so the calculation time is increased.

Other results can be illustrated in the used software, as well for instance effective stress and distortion in Fig. 14 and Fig. 15, respectively. Effective stress distribution form is similar to the heat flux's one. The magnified distortions in Fig. 15, generated by occurring stresses, show that they are higher by less weld spot trajectories because application of more weld spots is acting like pressing forces onto the sheets. Naturally, activated clampings play during that big roles. 


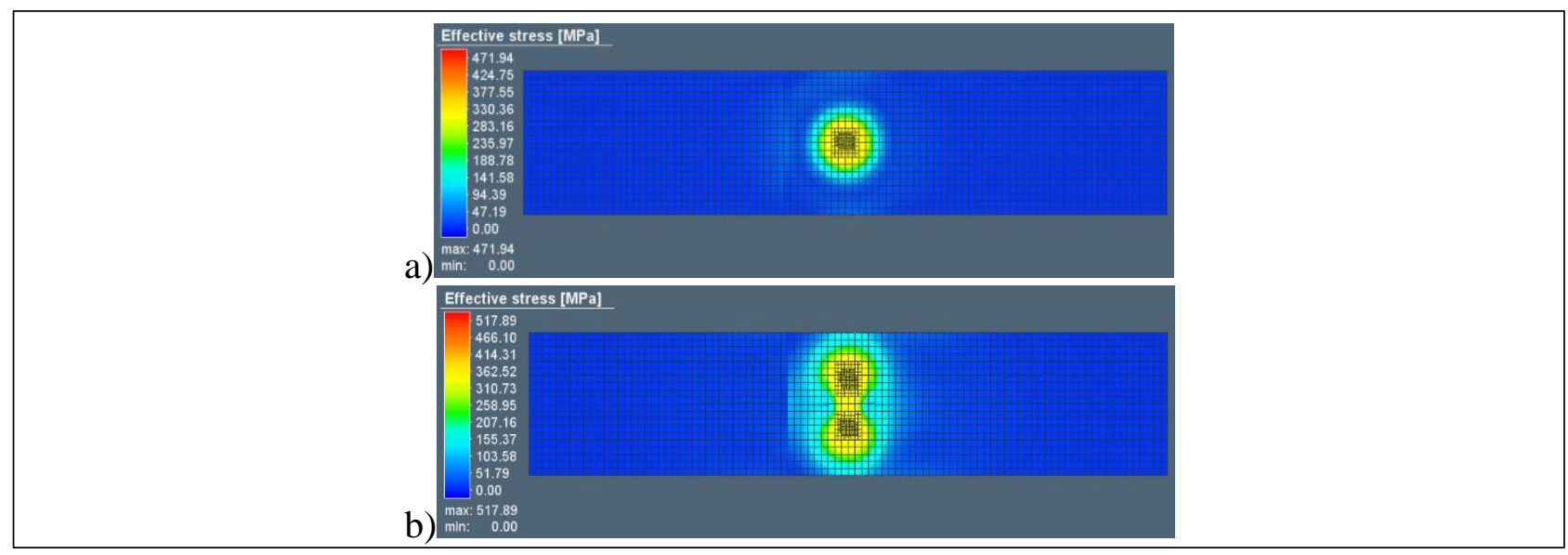

Fig. 14. Effective Stress Distribution after $10 \mathrm{~s}$ on the Sheets for a) Type 2 and b) Type 4

a)

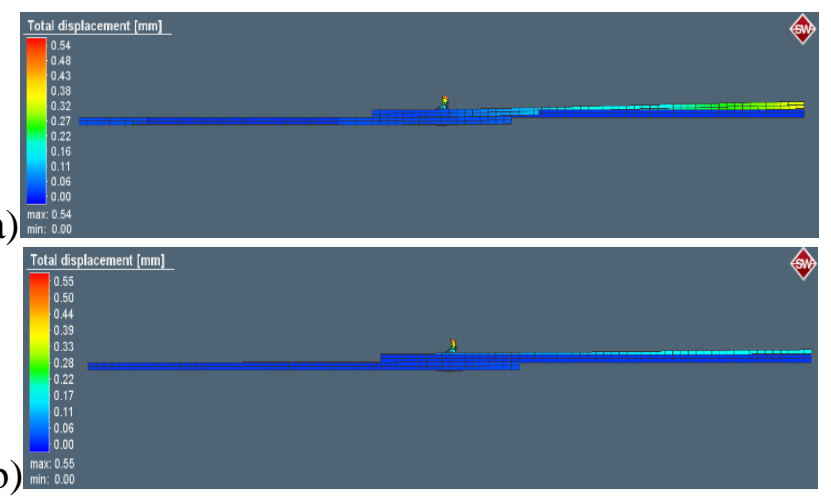

Fig. 15. Displacements after $10 \mathrm{~s}$ on the Sheets for (a) Type 2 and (b) Type 4 with a scale factor ' 6 '

\section{Discussion of the Results in the Context of Industry 4.0}

The FEA work in that study is only an example for the start of data processing during the whole production process. So, that phase can be accepted as the start of a design process and act as stage of the hierarchical process or can be generated during the manufacturing tried with several parameters. Then the computed analysis results can be reflected and dispersed to other elements of the production with the tools of Industry 4.0, for instance the results can affect even to logistics. But the most operative benefits can be achieved if the analytic foresights can be processed by other production machines or production processes. For instance, a little change in one laser beam welding process can affect on the energy efficiency of the whole factory. The importance of such a case can be calculated directly with other intelligent components of a factory managed with the Industry 4.0. Some details accumulate and determine the whole process. Also, that hierarchical process can be thought as a duration including production details interconnected and processed in an integrative manner to increase the production efficiency and to decrease production costs such as energy.

The efficiency and successes raise if all the used computational software are used more actively by connecting them in a right way. During that, the operation of each 
software is significant, as well. In that study, the laser beam welding is selected as the manufacturing analysis process. For instance, it is another issue how close the results are to the real life. Modelling the welding scenario with the true precise welding parameters and the implementation of workshop conditions such as, modifying the workpiece through surface preparation, decreasing the pressure in the welding zone and modifying the process, are too considerable. Taking phase change, spatter formation, laser irradiation and vapor dynamics are other significant values which should be considered.

The FEM results as a computational simulation model show expected heat distribution results. The results should be commented more detailed if heat flux types could be separated into their types: convective, radiative and contact heat transfer. High energy flows per affected area are observed by laser welding. Moreover, if that application were a real implementation for a problem-part of a factory for example, more precise energy savings conclusions would be reached. Also, it is here important to care of definite stages of a process and connect them and feed them with a stabile data flow towards Big Data and IoT. During all these acts, considering the basis valid standards is a must, for instance ISO 50001, 9001 and 14001. They can be evaluated in an integrative manner. Energy efficiency of the process can be related with Quality Standards directly through PDCA Cycle by considering the environmental standards. A compact software system valid for a factory working within Industry 4.0 can help by that situation whose result values are reflected to production system through even artificial intelligence tools.

\section{Conclusions}

Systematic approach and functionality must be provided through Industry 4.0. That study's main idea and principle can be applied to other manufacturing methods as well, such as deep drawing of sheet metal parts. The proposed compact software system can bring other features such as Tolerance Analysis and Production Optimization. As it is mentioned, it is here to important acquire an integrative system fed by automatization and managed with approaches like bottom-up idea. During that, connecting all the necessary production, management and logistic details will be very operative by caring about the functioning systems and rules through standards. The main disadvantage of providing such systems are the high costs and the need for the necessary qualified people. Also, the industrial ecosystem should be designed according to that. That is opening the door of Industry 5.0 by which other sectors will use tools such as biomaterials towards Human-Machine-Interaction more effectively by Augmented Reality.

The future studies can be about other manufacturing types including more detailed operations. Moreover, FEA simulations can be broadened for Laser Beam Welding with actual parameter trials in workshop. 


\section{Acknowledgements}

I present my thanks to Hexagon/MSC Software for the Simufact Welding free license, to Netform Muhendislik A.S. for the software license and information support and to IPG Photonics Eurasia Laser Products for the technical consultation.

\section{References}

Akopova, E. S. \& Przhedetskaya, N. V. (2019). The Algorithm of Managing the Process of Formation and Development of Industry 4.0 in the Modern Economic Systems in the Conditions of Knowledge Economy's Formation, In: Industry 4.0: Industrial Revolution of the 21st Century. Popkova, E. G., Ragulina Y. V. \& Bogoviz, A. V., (Ed.), pp. 31-53, Springer Nature, ISBN: 978-3319943091, Cham, Switzerland. DIN EN ISO 14001. (2015). Environmental management systems - Requirements with guidance for use (ISO 14001:2015); German and English version EN ISO 14001:2015. DIN EN ISO 14373, (2015). Resistance welding - Procedure for spot welding of uncoated and coated low carbon steels; German version.

DIN EN ISO 50001. (2018). Energy management systems - Requirements with guidance for use (ISO 50001:2018); German version EN ISO 50001:2018.

DIN ISO 50006. (2017). Energy management systems - Measuring energy performance using energy baselines $(\mathrm{EnB})$ and energy performance indicators $(\mathrm{EnPI})$ - General principles and guidance (ISO 50006:2014).

DIN SPEC 16593-1. (2018). RM-SA - Reference Model for Industrie 4.0 Service Architectures - Part 1: Basic Concepts of an Interaction-based Architecture; Text in English.

DIN SPEC 3103. (2019). Blockchain and distributed ledger technologies in application scenarios for Industrie 4.0.

Durakbasa, N., Bauer, J. \& Poszvek, G. (2017). Advanced Metrology and Intelligent Quality Automation for Industry 4.0-Based Precision Manufacturing Systems. Trans Tech Publications. Vol. 261, Aug. 2018, pp. 432-439. DOI= 10.4028/www.scientific.net/SSP.261.432.

Fabbro, R. (2013). Developments in Nd: YAG laser welding. Handbook of laser welding technologies. Katayama, S., (Ed.), pp. 47-72. Woodhead Publishing, ISBN: 978-0857092649, Philedelphia, USA.

Goldak, J. A. and Akhlagi, M. (2010a). Chapter I: Introduction. Computational Welding Mechanics. pp. 1-15. Springer, ISBN, New York, USA.

Goldak, J. A. and Akhlagi, M. (2010b). Chapter II: Computer Simulation of Welding Processes, Computational Welding Mechanics. pp. 16-69. Springer, ISBN: 9780387232874, New York, USA.

Gunal, M. M. (2019). Simulation and the Fourth Industrial Revolution. Simulation for Industry 4.0 Past Presence Future. Gunal, M. M., (Ed.), pp. 1-18. Springer Nature, ISBN: 978-3030041366, Cham, Switzerland.

Gunal, M. M. \& Karatas M. (2019). Industry 4.0, Digitisation in Manufacturing, and Simulation: A Review of the Literature. Simulation for Industry 4.0 Past Presence 
Future. Gunal, M. M. (Ed.), pp. 19-29. Springer Nature, ISBN: 978-3030041366, Cham, Switzerland.

Heston, T. (2015) Know Laser Weld Penetration-Now, Available from: https://www.thefabricator.com/thefabricator/article/laserwelding/know-laser-weld-penetration-now, Accessed on: 2020-09-15.

International Standard-Final Draft ISO/FDIS 50004. (2020). Energy management systems - Guidance for the implementation, maintenance and improvement of an ISO 50001 energy management system.

International Standard-ISO 50002. (2014). Energy audits - Requirements with guidance for use.

IPG Photonics Eurasia Laser Products-Database

Katayama, S. (2013). Introduction: fundamentals of laser welding. Handbook of laser welding technologies. Katayama, S. (Ed.), pp.3-16. Woodhead Publishing, ISBN: 9780857092649, Philadelphia, USA.

Kelly, S. M., Martukanitz, R. P. \& Reutzel, E. W. (2011). Minimizing buckling distortion in welding by hybrid laser-arc welding. Minimization of welding distortion and buckling Modelling and Implementation. Michaleris, P. (Ed.), pp. 241-272. Woodhead Publishing, ISBN: 978-1845696627, Cambridge, UK.

Kristensen, J. K. (2013). Applications of the laser welding in the shipbuilding industry. Handbook of laser welding technologies. Katayama, S. (Ed.), pp. 596-612. Woodhead Publishing, ISBN: 978-0857092649, Philadelphia, USA.

Landowski, M. (2019). Influence of Parameters of Laser Beam Welding on Structure of 2205 Duplex Stainless Steel. Advances in Materials Science. Vol. 19, No.1 (Mar. 2019), pp. 21-31. DOI= 10.2478/adms-2019-0002.

Mourtzis, D., Vasilakopoulos, A., Zervas E. \& Boli, N. (2019). Manufacturing System Design using Simulation in Metal Industry towards Education 4.0. Procedia Manufacturing, 9th Conference on Learning Factories. Vol. 31, pp. 155-161. DOI= 10.1016/j.promfg.2019.03.024.

NA, S-J. \& Cho, W-I. (2013). Developments in modelling and simulation of laser and hybrid laser welding. Handbook of laser welding technologies. Katayama, S. (Ed.), pp. 522-552. Woodhead Publishing, ISBN: 978-0857092649, Philadelphia, USA, 522552.

Quality management systems - Requirements (ISO 9001:2015). (2015). German and English version EN ISO 9001:2015.

Rodič, B. (2017). Industry 4.0 and The New Simulation Modelling Paradigm. Organizacija De Gruyter Open, Vol. 50, (Aug. 2017), pp. 193-207. DOI= 10.1515/orga-2017-0017.

Stanciu, E. M., Dumitru G.M., Pavalache, A. C., Pascu, A., Georgeta, A. \& Petre, D. (2010). Keyhole Formation during Laser Welding. Annals of DAAAM for 2010 \& Proceedings of the 21st International DAAAM Symposium, Katalinic, B. (Ed.). DAAAM International, ISBN: 978-3-901509-73-5, Vienna, Austria.

Szuhanek, Z. (2010). Mechanical Properties of Welded Orthodontic Metal Appliances. DAAAM International Scientific Book 2010. Katalinic, B. (Ed.), pp. 237-244. ISBN 978-3-901509-74-2, Vienna, Austria. 
Vanchukhina, L. I., Leybert, T. B., Khalikova, E. A., Rudneva, Y. R. \& Rogacheva A. M. (2019). Industry 4.0 and Closed-Loop Economy in the Context of Solving the Global Problems of Modern Times. Industry 4.0: Industrial Revolution of the 21st Century. Popkova, E. G., Ragulina Y. V., Bogoviz, A. V. (Ed.), pp. 31-53. Springer Nature, ISBN: 978-3319943091, Cham, Switzerland.

VDI 5600-Blatt 6 (Verein Deutscher Ingenieure-Richtlinien). (2017). Fertigungsmanagementsysteme (Manufacturing Execution Systems - MES) Energy Management with MES.

VDI 5600-Blatt 7 Entwurf (Verein Deutscher Ingenieure-Richtlinien). (2020). Fertigungsmanagementsysteme (Manufacturing Execution Systems - MES) MES und Industrie 4.0.

VDI/VDE 3714-Blatt 1 Entwurf (Verein Deutscher Ingenieure/Verband der Elektrotechnik Elektronik Informationstechnik-Richtlinien). (2019). Implementierung und Betrieb von Big-Data Anwendungen in der produzierenden Industrie Durchführung von Big-Data-Projekten.

VDI/VDE 3714-Blatt 1 Entwurf (Verein Deutscher Ingenieure/Verband der Elektrotechnik Elektronik Informationstechnik-Richtlinien). (2019). Implementierung und Betrieb von Big-Data Anwendungen in der produzierenden Industrie Datenqualitaet.

Vieira, A. A. C., Dias, L. M. S., Santos, M. Y., Pereira, G. A. B. \& Oliveira, J. A. 2019. Simulation of an automotive supply chain using big data, Computers \& Industrial Engineering, Vol. 137, pp. 1-14. DOI= 10.1016/j.cie.2019.106033.

Wang, H. (2013). Applications of the laser welding in the railway industry. Handbook of laser welding technologies. Katayama, S. (Ed.), pp. 575-595. Woodhead Publishing, ISBN: 978-0857092649, Philadelphia, USA.

Xin, X., Pereira, A. B., Amorim, J. \& Liao, J. (2017). Effects of Pulsed Nd:YAG Laser Welding Parameters on Penetration and Microstructure Characterization of a DP 1000 Steel Butt Joint. Metals. Vol. 7, No. 292, (Aug. 2017), pp. 1-18. DOI= 10.3390/met7080292.

Yilbas, B. S. 2013. Laser Welding of AISI 316 Steel: Microstructural and Stress Analysis. Journal of Manufacturing Science and Engineering. Vol. 135, (June 2013). pp. 1-10. DOI=10.1115/1.4024155. 